\title{
Schinzel-Giedion Midface-Retraction Syndrome
}

National Cancer Institute

\section{Source}

National Cancer Institute. Schinzel-Giedion Midface-Retraction Syndrome. NCI

Thesaurus. Code C129308.

An autosomal dominant disorder associated with mutation(s) in the SETBP1 gene, encoding SET-binding protein. It is characterized by unique facial features, including midface hypoplasia, skeletal abnormalities, and mental retardation. 